Z Gerontol Geriat 2022 · 55:597-602 https://doi.org/10.1007/s00391-021-01957-w Received: 7 January 2021 Accepted: 12 July 2021

Published online: 29 September 2021

(c) The Author(s) 2021

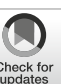

\section{Preventive treatment options for fear of falling within the Swiss healthcare system}

\author{
A position paper
}

\author{
Eric Lenouvel ${ }^{1,2} \cdot$ Lan Novak $^{1} \cdot$ Andreas Biedermann $^{3} \cdot$ Reto W. Kressig ${ }^{4} \cdot$ Stefan Klöppel' \\ ' University Hospital of Old Age Psychiatry and Psychotherapy, University of Bern, Bern, Switzerland \\ ${ }^{2}$ Graduate School for Health Sciences, University of Bern, Bern, Switzerland \\ ${ }^{3}$ Public Health Services, Bern, Switzerland \\ ${ }^{4}$ University Department of Geriatric Medicine FELIX PLATTER \& University of Basel, Basel, Switzerland
}

\title{
Abstract
}

Fear of falling (FoF) results in social, functional, physical, and psychological symptoms, including secondary disorders, such as depression and general anxiety disorder (GAD). A vicious cycle develops, where symptoms maintain and reinforce FoF and its consequences, including increasing the risk of falling. In this position paper, we suggest screening for FoF using the falls efficacy scale international (FES-I) questionnaire. The presence of a high score $(>23)$ warrants an investigation into frailty and exclusion of depression and GAD, during the clinical interview. Stratifying frailty, based on the Fried frailty criteria will guide treatment options based on the most significant health concerns. Frail older adults should first receive physiotherapy and exercise interventions, as physical disabilities are their most significant characteristic, while pre-frail and non-frail older adults should receive multicomponent interventions, consisting of cognitive behavioral therapy (CBT) with physical exercise. The non-frail with predominantly GAD and depression should receive specialized CBT interventions. Currently, only exercise interventions are available for FoF treatment in Switzerland. Although some exercise interventions use CBT elements, such as goal setting and reflections on behavior and feelings, they are not systematically used, are not part of a quality-assured procedure, and do not address the psychological-cognitive aspects of FoF. As the pre-frail and non-frail are the largest groups to use these services, adapting current exercise programs by incorporating a CBT component would be the most practical means to provide optimized care.

\section{Keywords}

A matter of balance Balance confidence $\cdot$ Falls efficacy $\cdot$ Cognitive behavioral therapy

\section{Background}

Disclaimer: all views expressed in this article are the opinions of the authors and are not an official position of any institute.

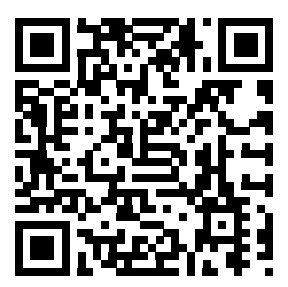

Scan QR code \& read article online
Fear of falling (FoF) is a "lasting concern about falling that leads to an individual avoiding activities that he/she remains capable of performing [32]." It is considered an entity of falls-related psychological concerns, which also includes falls efficacy, which describes how a person perceives their ability not to fall [24]. The FoF, depending on the number of previous falls, is present in up to $86 \%$ of older adults (65 years and over) [36]. Additionally, there is increased prevalence of FoF among those suffering from mild to moderate cognitive impairment and among the frail [21, 23, 29]. To put these figures into perspective, up to $35 \%$ of older adults will fall each year, increasing in frequency with age and frailty [34].

The FoF has been suggested to be unidirectionally linked to falls efficacy and anxiety, in that high levels of FoF lead to lowlevels of falls efficacy, resulting in a maladaptive nature of FoF, where daily activities appear to have excessive risk for falling 


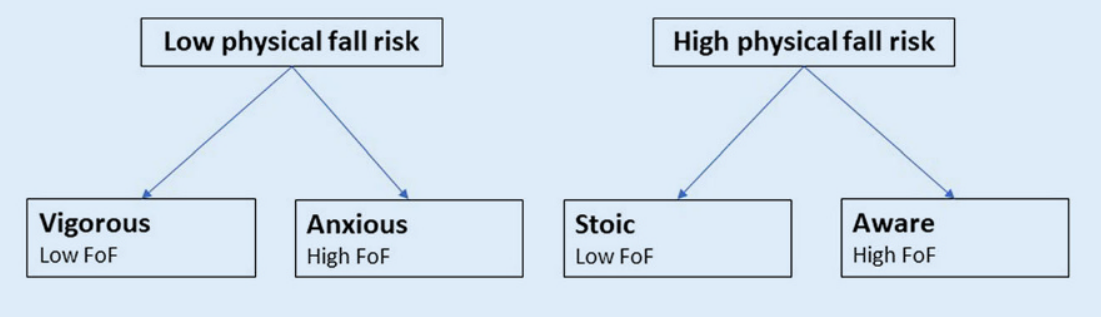

Fig. 1 \ Simplified Delbaere classification tree, modified from Delbaere et al. [5]

[1]. High levels of FoF result in social, functional, physical, and psychological symptoms, such as avoidance, decrease in social participation, ability to perform activities of daily living (ADLs), quality of life, and self-confidence, increased rates of depression and general anxiety $[29,36]$. These various sequelae have been shown to develop into a vicious cycle, where symptoms maintain and reinforce FoF, and its consequences, including increasing the risk of falling [9]; however, low levels of FoF have been suggested by some authors to even protect against future falls [1].

Frailty is a condition of decreased functional reserve leading to a vulnerable state and is considered the stage before disability [18]. Due to the expanding old age population throughout the world, frailty is an emerging global health challenge. The levels of frailty among older adults, and as such their treatment needs, are highly heterogeneous $[8,18]$. Although different models of frailty exist with no current consensus, many describe a continuum between healthy and frail, such as the functional spectrum by Speechley and Tinetti, 1991, or the more recent Fried frailty criteria, commonly used in studies of older adults $[10,20]$. The Fried criteria group older adults into non-frail, pre-frail, and frail. Frailty occurs when three or more criteria are met of weakness, slow gait, low physical activity, exhaustion, and unintentional weight loss, whereas pre-frail means that one to two of these criteria are fulfilled [10].

The FoF is associated with frailty and various health characteristics [21]. Delbaere et al. classified older adults based on the disparity between the FoF level and physiological state; Vigorous-low FoF and low fall risk, anxious-high FoF and low fall risk, stoic - low FoF and high fall risk and aware-high FoF and high fall risk (see - Fig. 1; [5]). These groups are found in $29 \%, 11 \%, 20 \%$, and $40 \%$ of older adults living in the community, respectively, each having a rate of one or more falls during a 1 -year period of $20 \%$, $39 \%, 34 \%$, and $41 \%$, respectively [5]. The largest group with FoF, the aware, have physical limitations leading to high fall risk that would likely classify them as at least pre-frail older adults according to the Fried criteria. Older adults are expected to progress through the frailty spectrum.

Although FoF is associated with geriatric multimorbidity and immobility, FoF is also associated with both anxiety and depression $[5,7,26]$. The FoF has been associated with a wide range of nonfallrelated concerns, such as being robbed, forgetting appointments, having financial problems, losing one's personal identity or independence $[13,14,35]$. This wide range of concerns resembles the excessive, difficult to control, and disturbing anxiety found in general anxiety disorder (GAD). Late life anxiety might present as FoF, whereas it may have presented with other symptoms in earlier phases of life. A study by Payette et al. even suggested that FoF has a greater association to GAD than to actual fall risk [26]. The association of FoF with depression has also been demonstrated in several studies, although it is not clear whether depression is the consequence of FoF or vice versa $[7,11$, $15,16]$. As a consequence, and because GAD and depression can be the cause of FoF at least in some patients, screening, diagnosing, and possibly treating primary psychiatric disorders should be undertaken [28].

Often overlooked in favor of somatic causes of reduced mobility and increased frailty, FoF identification and treatment is important, due to its prevalence and the symptoms it can cause even among those who have not fallen, to prevent and treat the physical and psychological sequalae [29]. Despite this, there is no generally accepted consensus on screening and treating FoF. Sufficient studies are lacking to synthesize evidence for best screening and treatment options in Switzerland. In this position paper, we suggest that screening for FoF using the falls efficacy scale international (FES-I) questionnaire, as well as screening for depression and GAD in the clinical interview, while stratifying frailty, based on the Fried Frailty criteria, will help identify FoF and guide treatment options based on core needs. This position paper is based on significant contributions from scientific literature and consensus opinion among the multidisciplinary group of expert coauthors.

\section{Treatment options for FoF}

The FoF is an interdisciplinary problem. Geriatricians and family physicians, in being primary care practitioners, typically manage the somatic sequelae, falls, and immobility resulting from FoF. Psychiatrists respond to the fear and anxiety response to the thought of falling, and the resulting vicious cycles leading to psychiatric comorbidities. As such, treatment options should address both the somatic and psychiatric needs of individuals, while focusing on their greatest needs. Cognitive behavioral therapy (CBT), multicomponent (CBT combined with exercise), and exercise interventions have been developed to treat FoF $[4,19,22]$. CBT is a form of psychotherapy that seeks to modify dysfunctional beliefs and behavior through various psychotherapeutic techniques [22]. Exercise interventions are planned, structured, repetitive, and purposive physical activities aimed at improving or maintaining one or more components of physical fitness [19]. Multicomponent interventions incorporate both CBT and exercise components into the interventions. Treatment of FoF aims to reduce the symptoms of FoF and reduce the associated fall risk factors [4]. These interventions should aim to decrease the number of falls, increase strength, gait, balance and mood, give a better ability to get up after a fall, and have an increased number of activities performed without falling $[19,30]$. 
Parry et al. developed a purely CBT intervention for FoF, given individually at home over $45 \mathrm{~min}$ on a weekly basis for 8 weeks with a follow-up session at 6 months, by specially trained healthcare assistants. A CBT intervention with an exercise component for FoF was first developed by Tennstedt et al. and adapted in different countries [4, 22, 25, 31]. Tennstedt's intervention uses three levels of facilitators; a coach, who gives the class, receives $8 \mathrm{~h}$ of training. They are trained by master trainers, who have completed 2 full days of training by lead trainers, who are specialists in the field. This structure permits a cost-effective solution. This demonstrates how inexperienced therapists can be just as effective as expert therapists when a treatment plan is followed [33]. Exercise interventions such as Tai Chi, balance training or dancing likely increases physical capabilities and improves confidence to perform activities [19]. They have been shown to reduce FoF without increasing the risk of falls. Sessions are given by experts one or more times per week, for 10-13 weeks in many protocols. In Switzerland, Tai chi coaches receive certification from Tai Chi schools after following regular training over two semesters and after a final examination. Meta-analyses have shown that the effect sizes of psychotherapy, exercise interventions, and their combination in multicomponent interventions overlap [4, $19,22]$. This effect is most commonly measured using the Falls Efficacy Scale Internation (FES-I), which screens for the level of concern regarding falling that an individual may have $[19,32]$. A score of $>23$ for the 16-item FES-I scale corresponds to a high concern for falling, equating to a high FoF [6].

There is insufficient evidence to tailor specific FoF interventions based on the level of frailty of an individual with FoF. Current best practice would therefore target treatment towards their most significant health concern [8, 21, 22]. Using the Fried criteria therefore should optimize treatment and focuses the intervention to address the greatest needs of the individual. Frail older adults primarily have physical disabilities that would lead to an increased fall risk, such as sarcopenia. It is therefore reasonable to first offer this group physiotherapy and exercise interventions to help restore or maintain strength and balance. Those in the pre-frail stage are in the process of losing their physical abilities, increasing risk of falls, regardless of the level of FoF. Multicomponent interventions should allow this group to best preserve their abilities. They may serve as an opportunity to address physical problems as well as address FoF's vicious psychological cycles, through the CBT component [21]. Anxiety is likely the primary manifestation of FoF in non-frail older adults. They do not yet have the physical limitations of the frail and avoid activities that they remain physically capable of performing. A multicomponent intervention would reinforce and maintain current physical capabilities through its exercise component, and the CBT component would address this more significant anxiety component. Non-frail older adults presenting predominantly with anxiety or depression will likely benefit from CBT interventions, such as that developed by Parry et al.

\section{Context in Switzerland}

In Switzerland, about 88,000 annual falls have been reported in people aged 65 years and over, and 1520 fall-related deaths per year were found between 2011 and 2015 [2]. The resultant health costs represent a significant economic burden, costing up to $1.5 \%$ of all healthcare expenditure [12]. In Switzerland, this should represent around 1.2 billion CHF [2].

Despite these costs and the prevalence of FoF, it is unlikely to be recognized. Physicians are pressed for time and other resources, with varying attitudes towards mental health, and with a risk to misinterpret the results of measurement tools [17, 27]. This may contribute towards barriers to participation. There may be denial or underestimation of the risk of falling, presence of FoF, fatalism (e.g. too old to start), social stigma, and inaccessible information [3]. Although there are no specific federal directives for preventive medicine in old age, several organizations have engaged in fall prevention, supported by both health insurers and cantonal efforts. In this respect organizations such as the Bureau de Prévention des Accidents (BPA), Promotion Santé Suisse, Pro Senec- tute, Physioswiss, the Swiss Association of Ergotherapists (ErgotherapeutInnenVerband Schweiz), Rheumaliga Schweiz have either individually or in partnership, introduced programs like Sicher gehen-Sicher stehen (Sichergehen.ch), and StoppSturz aimed at developing, improving quality, and providing fall prevention programs in the old age. Of particular note, StoppSturz is currently developing, as part of its fall prevention program, guidelines for the management of FoF. StoppSturz aims to help healthcare providers to recognize, clarify, prevent, and treat underlying causes of falls. In forming an interdisciplinary expert committee, they aim at providing the highest quality tools and training for healthcare providers. The steering committee is comprised of general practitioners, nurses, ergotherapists, physiotherapists, and geriatricians. The precise numbers of participants in each fall prevention program and total number of fall prevention groups are not publicly known. This is likely due to the fact that many exercise groups for seniors include balance and strength training but do not consider fall prevention their primary goal.

\section{Treatment options for FoF within the Swiss context}

Currently it appears that there are few specific FoF interventions available in Switzerland. SturzZentrum Schweiz, based in Zurich, offers targeted evidencebased interventions for FoF, and training for coaches. Interventions offered are Tai Chi, Dalcroze eurhythmics training, dance match home-based programs, and strength and balance training. Pro Senectute, provides Tai Chi classes specific for FoF, and FitGym specific for fall prevention. The Schweizerischer Turnverband offers "Turnen Erwachsene" exercise classes. Sichergehen.ch, a comprehensive website listing various fall prevention activities for older adults throughout Switzerland, lists different evidence-based interventions for fall prevention. To date, Sichergehen.ch only has exercise interventions. Although some Sichergehen.ch exercise interventions use elements found in CBT, such as goal setting and reflections on behaviour and feelings, they are not systematically 


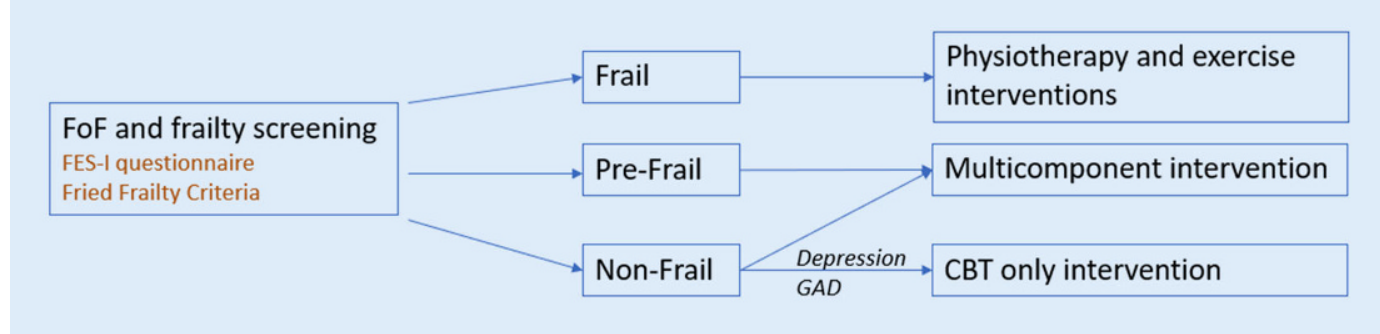

Fig. $2<$ Treatment algorithm of FoF

used, are not part of a quality assured procedure, and do not address the psychological cognitive aspects of FoF. CBT interventions or multicomponent interventions for FoF are not known to be given in Switzerland.

\section{Opportunities to develop a multicomponent intervention for the Swiss context}

Many patients with high levels of FoF using the fall prevention exercise programs would likely benefit from a multicomponent intervention. The adaptation of a CBT component to currently existing programs would likely be the most practical means of reaching the greatest number of individuals. Developing multicomponent interventions for FoF may incorporate validated FoF treatment models, such as Tennstedt et al.'s "A matter of balance $\odot$ ", by adapting them to currently available exercise interventions given by the Rheumaliga Schweiz, Pro Senectute, or the Schweizerischer Turnverband [31]. This adapted multicomponent model would therefore correspond to the Swiss context. Primary healthcare providers who screen for FoF and frailty could then have more options on treating FoF and guiding their patients towards an optimized care, as shown in - Fig. 2. Healthcare providers can administer the FES-I questionnaires and determine the Fried frailty criteria. If the FES-I questionnaire scores greater than 23 , then based on the Fried frailty criteria, optimized treatment could be suggested; physiotherapy and exercise interventions for the frail, combined CBT and exercise interventions for the pre-frail and nonfrail, and CBT interventions for the nonfrail with primarily psychiatric symptoms of depression and anxiety, as identified during clinical interviewing. In order to address the fall prevention needs of the vigorous group, they can be encouraged to pursue currently available fall prevention programs. Additionally, as the fall prevention programs typically consist of exercise interventions, there is potential to develop a cognitive intervention component for these interventions, focusing on learning from previous or near falls.

\section{Conclusion}

Fear of falling is a prevalent problem among older adults that creates a vicious cycle leading to the development of physical and mental comorbidities. Targeting treatment when there is a high concern for falling (FES-I>23), based on the Fried frailty criteria will optimize treatment. Frail older adults should first receive physiotherapy and exercise interventions, as physical disabilities are their most significant characteristic, while prefrail and non-frail older adults should receive multicomponent cognitive behavioral therapy (CBT) exercise interventions. The non-frail with predominantly anxiety and depressive symptoms should receive CBT interventions. Incorporating CBT elements in currently validated exercise interventions can establish multicomponent interventions specific for the Swiss context.

\section{Corresponding address}

Dr. Eric Lenouvel, BSc., MSc., M.D.

University Hospital of Old Age Psychiatry and Psychotherapy, University of Bern Murtenstraße 21, 3008 Bern, Switzerland eric.lenouvel@upd.unibe.ch

Funding. Sources of support: this work was supported within the financial scope of the University Hospital of Old Age Psychiatry and Psychotherapy of the University of Bern. No public, commercial, or non-profit sectors provided any specific grants for this work.
Author Contribution. EL, LN, AB, RK, SK article concept and design, and manuscript revision. EL, SK drafting article. All authors assisted in preparing and approving the final manuscript.

Funding. Open access funding provided by University of Bern

\section{Declarations}

Conflict of interest. E. Lenouvel, L. Novak, A. Biedermann, R.W. Kressig and S. Klöppel declare that they have no competing interests.

Ethical standards. For this article no studies with human participants or animals were performed by any of the authors. All studies performed were in accordance with the ethical standards indicated in each case.

Open Access. This article is licensed under a Creative Commons Attribution 4.0 International License, which permits use, sharing, adaptation, distribution and reproduction in any medium or format, as long as you give appropriate credit to the original author(s) and the source, provide a link to the Creative Commons licence, and indicate if changes were made. The images or other third party material in this article are included in the article's Creative Commons licence, unless indicated otherwise in a credit line to the material. If material is not included in the article's Creative Commons licence and your intended use is not permitted by statutory regulation or exceeds the permitted use, you will need to obtain permission directly from the copyright holder. To view a copy of this licence, visit http://creativecommons.org/licenses/by/4.0/.

\section{References}

1. Adamczewska N, Nyman SR (2018) A new approach to fear of falls from connections with the posttraumatic stress disorder literature. Gerontol Geriatr Med 4:1-7. https://doi.org/10.1177/ 2333721418796238

2. BPA (2019) Blessés par chute dans l'habitat et durant les loisirs, selon l'âge et le sexe. Beratungsstelle für Unfallverhütung, UHF.T.10

3. Cavill NA, Foster CEM (2018) Enablers and barriers to older people's participation in strength and balance activities: a review of reviews. J Frailty Sarcopenia Falls 3:105-113. https://doi.org/10. 22540/JFSF-03-105

4. Chua CHM, Jiang Y, Lim DS et al (2019) Effectiveness of cognitive behavior therapy-based multicomponent interventions on fear of falling among community-dwelling older adults: a systematic 
review and meta-analysis. J Adv Nurs. https://doi. org/10.1111/jan. 14150

5. Delbaere K, Close JCT, Brodaty H et al (2010a) Determinants of disparities between perceived and physiological risk of falling among elderly people: cohort study. BMJ 341:c4165. https://doi. org $/ 10.1136 / \mathrm{bmj} . \mathrm{c} 4165$

6. Delbaere K, Close JCT, Mikolaizak AS et al (2010b) The Falls Efficacy Scale International (FES-I). A comprehensive longitudinal validation study. Age Ageing 39:210-216. https://doi.org/10.1093/ ageing/afp225

7. Denkinger MD, Lukas A, Nikolaus T et al (2015) Factors associated with fear of falling and associated activity restriction in communitydwelling older adults: a systematic review. Am J Geriatr Psychiatry 23:72-86. https://doi.org/10. 1016/j.jagp.2014.03.002

8. Dent $\mathrm{E}$, Martin FC, Bergman $\mathrm{H}$ et al (2019) Management of frailty: opportunities, challenges, and future directions. Lancet 394:1376-1386. https://doi.org/10.1016/S0140-6736(19)31785-4

9. Deshpande N, Metter EJ, Bandinelli S et al (2008) Psychological, physical, and sensory correlates of fear of falling and consequent activity restriction in the elderly: the InCHIANTI study. Am J Phys Med Rehabil 87:354-362. https://doi.org/10.1097/ PHM.0b013e31815e6e9b

10. Fried LP, Tangen CM, Walston J et al (2001) Frailty in older adults: evidence for a phenotype. J Gerontol A Biol Sci Med Sci 56:M146-M156. https://doi.org/ 10.1093/gerona/56.3.m146

11. Gagnon N, Flint AJ, Naglie G et al (2005) Affective correlates of fear of falling in elderly persons. Am J Geriatr Psychiatry 13:7-14. https://doi.org/10. 1176/appi.ajgp.13.1.7

12. Heinrich S, Rapp K, Rissmann U et al (2010) Cost of falls in old age: a systematic review. Osteoporos Int 21:891-902. https://doi.org/10.1007/s00198009-1100-1

13. Hoang OTT, Jullamate $\mathrm{P}$, Piphatvanitcha $\mathrm{N}$ et al (2017) Factors related to fear of falling among community-dwelling older adults. J Clin Nurs 26:68-76. https://doi.org/10.1111/jocn.13337

14. Howland J, Peterson EW, Levin WC et al (1993) Fear of falling among the community-dwelling elderly. J Aging Health 5:229-243. https://doi.org/ 10.1177/089826439300500205

15. Hughes CC, Kneebone II, Jones F et al (2015) A theoretical and empirical review of psychological factors associated with falls-related psychological concerns in community-dwelling older people. Int Psychogeriatr 27:1071-1087. https://doi.org/10. 1017/S1041610214002701

16. laboni A, Banez C, Lam R et al (2015) Depression and outcome of fear of falling in a falls prevention program. Am J Geriatr Psychiatry 23:1088-1097. https://doi.org/10.1016/j.jagp.2015.02.006

17. Jung $D$ (2008) Fear of falling in older adults: comprehensive review. Asian Nurs Res 2:214-222. https://doi.org/10.1016/S1976-1317(09)60003-7

18. Junius-Walker $U$, Onder $G$, Soleymani $D$ et al (2018) The essence of frailty: a systematic review and qualitative synthesis on frailty concepts and definitions. Eur J Intern Med 56:3-10. https://doi. org/10.1016/j.ejim.2018.04.023

19. Kendrick D, Kumar A, Carpenter $\mathrm{H}$ et al (2014) Exercise for reducing fear of falling in older people living in the community. Cochrane Database Syst Rev 11:CD9848. https://doi.org/10.1002/ 14651858.CD009848.pub2

20. Kojima G, Liljas AEM, lliffe S (2019) Frailty syndrome: implications and challenges for health

\section{Präventive Behandlungsoptionen bei Sturzangst im Schweizer Gesundheitssystem. Ein Positionspapier}

Sturzangst führt zu sozialen, funktionellen, körperlichen und psychischen Symptomen, einschließlich sekundärer Störungen, wie Depression und generalisierte Angststörung (GAS). Es entsteht ein Teufelskreis, bei dem die Symptome die Sturzangst und ihre Folgen, einschließlich der Erhöhung des Sturzrisikos, aufrechterhalten und verstärken. In diesem Positionspapier schlagen wir vor, ein Screening auf Sturzangst mit dem Fragebogen Falls Efficacy Scale International (FES-I) durchzuführen. Das Vorhandensein eines hohen Wertes ( $>23$ ) rechtfertigt eine Untersuchung auf Gebrechlichkeit und erfordert den Ausschluss von Depression und GAS im Rahmen eines klinischen Interviews. Die Stratifizierung der Gebrechlichkeit, basierend auf den Fried-Kriterien für Gebrechlichkeit, leitet die Behandlungsoptionen basierend auf den wichtigsten Gesundheitsproblemen. Gebrechliche ältere Erwachsene sollten zuerst Physiotherapie und Bewegungsinterventionen erhalten, da körperliche Einschränkungen ihr wichtigstes Merkmal sind, während nicht gebrechliche ältere Erwachsene und solche mit Vorstufen von Gebrechlichkeit eine MultikomponentenIntervention erhalten sollten, bestehend aus kognitiver Verhaltenstherapie (CBT) mit körperlicher Bewegung. Nicht gebrechliche Menschen mit überwiegend GAD und Depressionen sollten spezielle CBT-Interventionen erhalten. Derzeit sind in der Schweiz nur Bewegungsinterventionen für die Behandlung von Sturzangst verfügbar. Obwohl einige Übungsinterventionen CBT-Elemente verwenden, wie z.B. Zielsetzung und Reflexion über Verhalten und Gefühle, werden diese nicht systematisch eingesetzt, sind nicht Teil eines qualitätsgesicherten Verfahrens und gehen nicht auf die psychologischkognitiven Aspekte von Sturzangst ein. Da Personen ohne bzw. mit Vorstufen von Gebrechlichkeit die größten Gruppen darstellen, die diese Dienste in Anspruch nehmen, wäre die Anpassung aktueller Trainingsprogramme durch Einbindung einer CBT-Komponente das praktischste Mittel, um eine optimierte Versorgung zu gewährleisten.

\section{Schlüsselwörter}

A matter of balance · Gleichgewichtsvertrauen · Sturzprävention · Kognitive Verhaltenstherapie

care policy. Risk Manag Healthc Policy 12:23-30. https://doi.org/10.2147/RMHP.S168750

21. Kressig RW, Wolf SL, Sattin RW et al (2001) Associations of demographic, functional, and behavioral characteristics with activity-related fear of falling among older adults transitioning to frailty. J Am Geriatr Soc 49:1456-1462. https://doi org/10.1046/j.1532-5415.2001.4911237.x

22. Liu T-W, Ng GYF, Chung RCK et al (2018) Cognitive behavioural therapy for fear of falling and balance among older people: a systematic review and meta-analysis. Age Ageing 47:520-527. https:// doi.org/10.1093/ageing/afy010

23. de Melo Borges S, Radanovic M, Forlenza OV (2015) Fear of falling and falls in older adults with mild cognitive impairment and Alzheimer's disease. Neuropsychol Dev Cogn B Aging Neuropsychol Cogn 22:312-321. https://doi.org/10.1080/ 13825585.2014.933770

24. Moore DS, Ellis R (2008) Measurement of fallrelated psychological constructs among independent-living older adults: a review of the research literature. Aging Ment Health 12:684-699. https:// doi.org/10.1080/13607860802148855

25. Parry SW, Bamford C, Deary V et al. (2016) Cognitive-behavioural therapy-based intervention to reduce fear of falling in older people: therapy development and randomised controlled trial - the Strategies for Increasing Independence, Confidence and Energy (STRIDE) study. Health
Technol Assess 2016;20(56). https://doi.org/10 3310/hta20560

26. Payette M-C, Bélanger C, Benyebdri F et al (2017) The association between generalized anxiety disorder, subthreshold anxiety symptoms and fear of falling among older adults: preliminary results from a pilot study. Clin Gerontol 40:197-206. https://doi.org/10.1080/07317115.2017.1296523

27. van Rijswijk $E$, van Hout $H$, van de Lisdonk $E$ et al (2009) Barriers in recognising, diagnosing and managing depressive and anxiety disorders as experienced by family physicians; a focus group study. BMC Fam Pract 10:52. https://doi.org/10. 1186/1471-2296-10-52

28. Scarlett L, Baikie E, Chan SWY (2019) Fear of falling and emotional regulation in older adults. Aging Ment Health 23:1684-1690. https://doi.org/10. 1080/13607863.2018.1506749

29. Scheffer AC, Schuurmans MJ, van Dijk $\mathrm{N}$ et al (2008) Fear of falling: measurement strategy, prevalence, risk factors and consequences among older persons. Age Ageing 37:19-24. https://doi. org/10.1093/ageing/afm 169

30. Sherrington C, Whitney JC, Lord SR et al (2008) Effective exercise for the prevention of falls: a systematic review and meta-analysis. J Am Geriatr Soc 56:2234-2243. https://doi.org/10. 1111/j.1532-5415.2008.02014.x

31. Tennstedt SJ, Howland M, Lachman E et al. (1998) A Randomized Controlled Trial of a Group 


\section{Fachnachrichten}

Intervention to Reduce Fear of Falling and Associated Activity Restriction in Older Adults. J Gerontol B Psychol Sci Soc Sci 53B(6) P384-P392. https://doi.org/10.1093/geronb/53B.6.P384

32. Tinetti ME, Powell $L$ (1993) Fear of falling and low self-efficacy: a case of dependence in elderly persons. J Gerontol 48(Spec):35-38. https://doi. org/10.1093/geronj/48.special_issue.35

33. Tracey TJG, Wampold BE, Lichtenberg JW et al (2014) Expertise in psychotherapy: an elusivegoal? Am Psychol 69:218-229. https://doi.org/10.1037/ a0035099

34. World Health Organization (2020) Ageing and lifecourse. Falls prevention in older age. WHO, Geneva

35. Yardley L, Beyer N, Hauer K et al (2005) Development and initial validation of the Falls Efficacy Scale-International (FES-I). Age Ageing 34:614-619. https://doi.org/10.1093/ageing/ afi196

36. Zijlstra GAR, van Haastregt JCM, van Eijk JTM et al (2007) Prevalence and correlates of fear of falling, and associated avoidance of activity in the general population of community-living older people. Age Ageing 36:304-309. https://doi.org/10.1093/ ageing/afm021

\section{Krebsinformationen in Leichter Sprache}

Zwei neue, kostenfrei erhältliche Bücher in Leichter Sprache klären als Bildergeschichten über Krebs und dessen Vorsorge auf.

Unter Menschen mit geistiger Behinderung ist die Inanspruchnahme von Früherkennungsmaßnahmen allgemein und von Krebsfrüherkennungsmaßnahmen im Speziellen geringer. Erschwerend kommen Kommunikationsschwierigkeiten und fehlende Beteiligungsmöglichkeiten der Betroffenen im deutschen Versorgungssystem dazu, das auf Menschen ohne Beeinträchtigungen ausgelegt ist.

Die Deutsche Krebsgesellschaft und die Bundesvereinigung Lebenshilfe haben sich daher zum Ziel gesetzt, eine verständliche Aufklärung über Früherkennungs- und Therapiemöglichkeiten von Krebs zu leisten und damit die Teilhabe von Menschen mit geistiger Beeinträchtigung zu verbessern.

Zu diesem Zweck wurde in einem gemeinsamen Projekt zwei französischsprachige Broschüren zur Akutbehandlung und zur Früherkennung - entwickelt von der gemeinnützigen Organisation Oncodéfi - unter Beteiligung von Ärzt*innen und Menschen mit geistiger Behinderung ins Deutsche übersetzt und an die hiesige Versorgungssituation angepasst. Dieses Projekt wird von der Deutschen Krebsstiftung und der Techniker Krankenkasse gefördert.

Die beiden Bücher (in einem handlichen Format, 90 bzw. 110 Seiten) sind als Bildergeschichten angelegt. Sie vermitteln den Leser*innen beispielhaft, welche Arten von Krebsvorsorgen es gibt und wie eine Krebsbehandlung ablaufen kann. Sie sind sowohl für den privaten Gebrauch als auch für den Einsatz im professionellen Kontext gedacht und werden kostenfrei zur Verfügung gestellt.

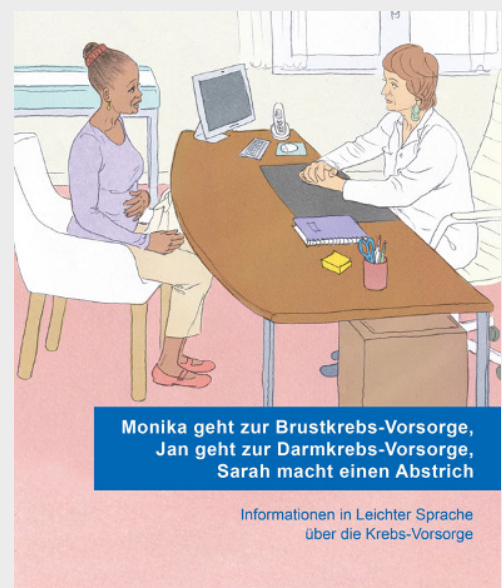

Buch zur Krebsvorsorge

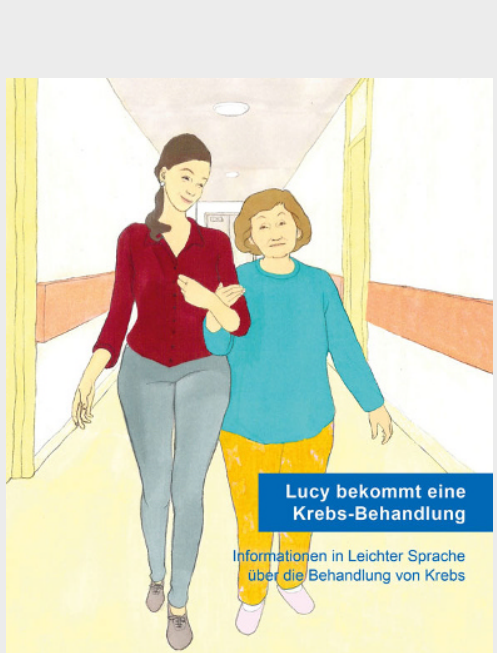

Buch zur Krebsbehandlung

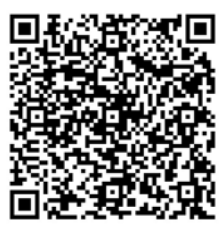

QR-Code scannen und online weiter lesen
Die Bücher werden im Set abgegeben (Vorsorge \& Akutbehandlung) und sind hier kostenfrei bestellbar (solange der Vorrat reicht):

www.lebenshilfe.de/krebsinformationen 